\title{
Ampliando o conceito de competência: contribuições às políticas públicas de certificação de competências
}

\author{
ARTURO CAVALCANTI CATUNDA*
}

\section{RESUMO}

Com base em dados coletados na rede estadual de ensino da Bahia, o presente artigo relata a investigação sobre a relação entre dois diferentes conceitos de competência, aferida por um processo de certificaçáo ocupacional para diretor escolar, e a proficiência de seus alunos em português, medida por avaliaçóes externas do ensino. Pôde-se confirmar que os conceitos de competência utilizados na investigação relacionam-se positivamente com o desempenho escolar - mesmo após a introdução de fatores de teste relacionados teoricamente com o desempenho escolar - e que essa relação é mais forte em contextos mais complexos de ensino. Entretanto, os achados da investigação indicam que modificaçóes no estabelecimento do conceito de competência têm influência na intensidade e significância das relaçôes estabelecidas com o resultado escolar. As conclusões da investigação contribuem para a elaboração de políticas públicas de certificação de competências no âmbito educacional, maior compreensão desse tema, assim como para a ampliação dos conhecimentos sobre fatores determinantes do desempenho escolar.

Palavras-chave: Competência profissional, Rendimento escolar, Políticas públicas, Diretor de escola.

* Coordenador Geral Acadêmico de cursos a distância do Centro Universitário Jorge Amado (Unijorge); Professor do Senai Cimatec (acatunda@yahoo.com.br). 


\section{RESUMEN}

Con base en datos recolectados en el sistema estadual de enseñanza de Bahía, el presente artículo relata una investigación sobre la relación entre dos diferentes conceptos de competencia, verificada por un proceso de certificación ocupacional para director escolar, y la proficiencia de sus alumnos en portugués, medida por evaluaciones externas de la enseñanza. Se pudo confirmar que los conceptos de competencia utilizados en la investigación se relacionan positivamente con el desempeño escolar - incluso después de introducir factores de test relacionados teóricamente con el desempeño escolar -, y que dicha relación es más fuerte en contextos más complejos de enseñanza. Sin embargo, los hallazgos de la investigación indican que algunas modificaciones en el establecimiento del concepto de competencia influencian la intensidad y significación de las relaciones establecidas con el resultado escolar. Las conclusiones de la investigación contribuyen con la elaboración de políticas públicas de certificación de competencias en el ámbito educativo, para una mayor comprensión de este tema, así como para la ampliación de los conocimientos sobre factores determinantes del desempeño escolar.

Palabras clave: Competencia profesional, Rendimiento escolar, Políticas públicas, Director de escuela.

\section{ABSTRACT}

Based on data collected in state schools in Bahia, this article reports on a research of the relationship between two different concepts of competence, as measured by an occupational certification process for school principals, and the proficiency of their students in the disciplines of Portuguese, as measured by external teaching assessments. We were able to confirm that the concepts of competence used in the study are positively related with school performance even after the introduction of testing factors theoretically related to school performance - and that this relationship is stronger in more complex teaching contexts. However, the findings of the investigation indicate that changes in establishing the concept of competence exert an influence on the intensity and significance of the relations established with the school results. The research findings contribute to the development of public policies of competences certification in education, to a greater understanding of this issue, as well as to the expansion of our knowledge of determinants of school performance.

Keywords: Professional competence, Educational achievement, Public policies, School principal. 


\section{INTRODUÇÃO}

Certificação de competência, ocupacional ou profissional, é um tema relativamente novo no Brasil. Segundo Mehedff (1999), algo ainda inexistente. Afora algumas iniciativas, localizadas em indústria de alta precisão; no sistema Senai; em algumas profissóes (como a promovida pela Ordem dos Advogados do Brasil); e para a emissão de licenças especiais (como a Carteira Nacional de Habilitação, emitida pelos Departamentos Estaduais de Trânsito), o tema começou a ser mais difundido no Brasil a partir do final da década de 90. De maneira geral, apenas em 2005 o governo federal conseguiu escrever um documento norteador de um Sistema Nacional de Certificação. Nesse documento, o governo estabelece proposta de uma linha mestre do fluxo e atores que irão operar o sistema no Brasil (Brasil, 2005).

A importância do tema certificação de pessoas está diretamente associada à educação da população, qualificação da mão de obra e competitividade das indústrias em um ambiente cada vez mais globalizado. D'Almeida (2003) identifica que, com o avanço da globalização, a questão da educação ganha maior evidência à medida que passa a ser vista como um critério relevante para que o país se torne e se mantenha competitivo.

As exigências do mercado de trabalho, por sua vez, modificam-se constantemente e novas competências são necessárias em função dos processos produtivos que estão em vigor. Nessa condição, a formação e a qualificação do trabalhador assumem contornos cada vez mais complexos na medida em que avançam a competitividade e a sociedade da informação.

A certificação de competência, nessa perspectiva, contribui de diversas maneiras. Para o profissional, é uma oportunidade de testar as suas competências e direcionar a sua formação continuada para as habilidades necessárias ao desempenho de uma ocupação ou profissão, assim como um instrumento de reconhecimento de competências adquiridas fora do sistema formal de ensino. Para as organizaçóes, é uma maneira de gerenciar pessoas por competência, contribuindo para a formação continuada do quadro de pessoal, alocaçáo de pessoas, aumento de eficiência e produtividade. Para a relação internacional, é uma forma de reconhecer competências de trabalhadores vindos de países com os quais se mantêm acordos trabalhistas e comerciais abertos. E, para a sociedade, é um instrumento de garantia na prestação de serviços de qualidade e defesa do direito do consumidor ou usuário.

$\mathrm{Na}$ Secretaria da Educação da Bahia (SEC), a certificação ocupacional foi adotada como política de provimento, valorização e incentivo à formação continuada dos profissionais da educação e, ao longo dos primeiros seis anos desta década, 
apresentou grande avanço em termos de quantidade de pessoas certificadas. Após a implantação de processos de certificação ocupacional para o cargo de dirigente escolar, vieram outros, como: professor alfabetizador, professor de disciplina para as séries finais do ensino fundamental e ensino médio, coordenador pedagógico e secretário escolar (Fundação..., 2005).

A certificação ocupacional foi implantada na SEC em 1999, como parte do programa de governo "Educar para Vencer". Nesse âmbito, foi criado o Projeto de Certificação Ocupacional de Profissionais da Educação, pela Fundação Luís Eduardo Magalhães (FLEM) para a SEC. Seu primeiro exame de certificação, aplicado em 2001, destinava-se a avaliar as competências básicas necessárias para o cargo de dirigente escolar.

Em 2007, com a mudança de gestão no governo do Estado da Bahia, a política de certificação ocupacional para o provimento do cargo de diretor escolar foi interrompida, sendo substituída por um sistema de eleição. Apesar disso, o modelo de certificação adotado pelo Estado da Bahia suscita novas experiências em outros Estados e cidades brasileiras, entre eles: Mato Grosso do Sul, Acre, Minas Gerais, São Paulo e na cidade de Campo Grande.

Dada a importância que a política de certificação de competências vem assumindo nas organizaçóes privadas e nos governos, assim como a novidade desse assunto no Brasil, este artigo almeja contribuir para o seu entendimento, trazendo resultados obtidos em pesquisa acadêmica, que investigou a relação entre competência ocupacional e desempenho organizacional, utilizando, para isso, dados empíricos da certificaçáo ocupacional de diretor escolar e do desempenho, em testes padronizados, dos alunos da rede estadual de ensino da Bahia.

O presente artigo, aliando-se a outros achados de pesquisas nacionais e internacionais, também busca agregar conhecimentos à literatura sobre a eficácia escolar. Neste sentido, a competência do diretor escolar é trabalhada como um fator que contribuirá para a produção de melhores resultados escolares.

Nas próximas seções serão apresentados os conceitos de certificação de competência e de desempenho escolar; o quadro operacional da pesquisa; os resultados encontrados; e as considerações finais.

\section{CONCEITOS}

A certificação de competências pode ser entendida como uma forma de um agente externo, credenciado e reconhecidamente idôneo entre as partes (trabalhador

110 - Est. Aval. Educ., São Paulo, v. 21, n. 45, p. 107-126, jan./abr. 2010 
e instituição patrocinadora), atestar que um profissional possui as competências que estão definidas em um padrão ou norma, não importando se foram adquiridas por meio da vivência profissional, da educação formal ou outra modalidade de desenvolvimento cognitivo.

Sendo a certificação uma forma de avaliaçáo das competências de um profissional para determinada ocupação, assim como a competência um conceito multifacetado, Mertens (1996) identifica três principais modelos de análise de competências que servem de base para um sistema de certificação: a condutiva, a funcional e a construtivista.

Este artigo abordará as competências do diretor escolar de duas maneiras: a primeira é baseada no processo de certificação ocupacional, realizado pela Fundação Luís Eduardo Magalhães (FLEM) para a Secretaria da Educação da Bahia (SEC). O conceito de competência utilizado nesse processo está associado ao modelo funcional de análise de competência. A segunda maneira de abordar as competências do diretor escolar está baseada no modelo construtivista de análise de competências, por meio da incorporação de atributos de competência ao conceito utilizado pela FLEM.

\section{Competências do diretor escolar no modelo funcional}

Com relação às competências de um dirigente escolar, no modelo funcional, além das atribuições para o exercício deste cargo estarem previstas na Lei Estadual n. 8.261 (Bahia, 2002), elas estão estabelecidas em um documento denominado Padróes de Competência oriundo do processo de análise de cargos da Agência de Certificação Ocupacional da FLEM (Fundação..., 2001).

As características do processo de certificação ocupacional da FLEM podem ser associadas ao método funcional. Essa associação é justificada pelos seguintes aspectos: 1) as competências descritas são competências básicas necessárias ao desempenho de determinada ocupação; 2) essas competências se originam a partir da descrição da função ou ocupação, com a participação dos próprios trabalhadores ocupantes do cargo; 3) as competências elencadas são, além daquelas necessárias ao desempenho da ocupação no âmbito organizacional, relacionadas ao contexto no qual a competência ocorre.

\section{Competências do Diretor Escolar no Modelo Construtivista}

A diferença entre o modelo funcional de análise de competência e o modelo construtivista está na incorporação, por este último, de atributos relacionados à 
experiência, à capacitação e à formação dos trabalhadores. "[...] Para a abordagem construtivista, a competência é criada no decorrer das experiências pessoais. É na construção do mundo que a pessoa desenvolve o seu projeto de vida e caminha da aptidão e da vocação para o êxito e a competência profissional [...]" (Organização..., 1999, p. 111). Nessa perspectiva, além das competências dos dirigentes escolares, analisadas pelo método funcional, são consideradas as trajetórias percorridas pelo dirigente, em particular. Trajetórias essas individuais e únicas, refletidas, em princípio, por meio dos atributos acima relacionados.

Para efeito dessa investigação, observando o caráter complexo de se mensurar trajetórias individuais na construçáo de competências, foram consideradas pertencentes à dimensão construtivista a experiência do diretor na função e na educação, a escolaridade e a capacitação, além dos atributos já relacionados na dimensão funcional. A figura 1 demonstra esse construto.

Figura 1 - Esquema de competências (funcional e construtivista) do diretor escolar*

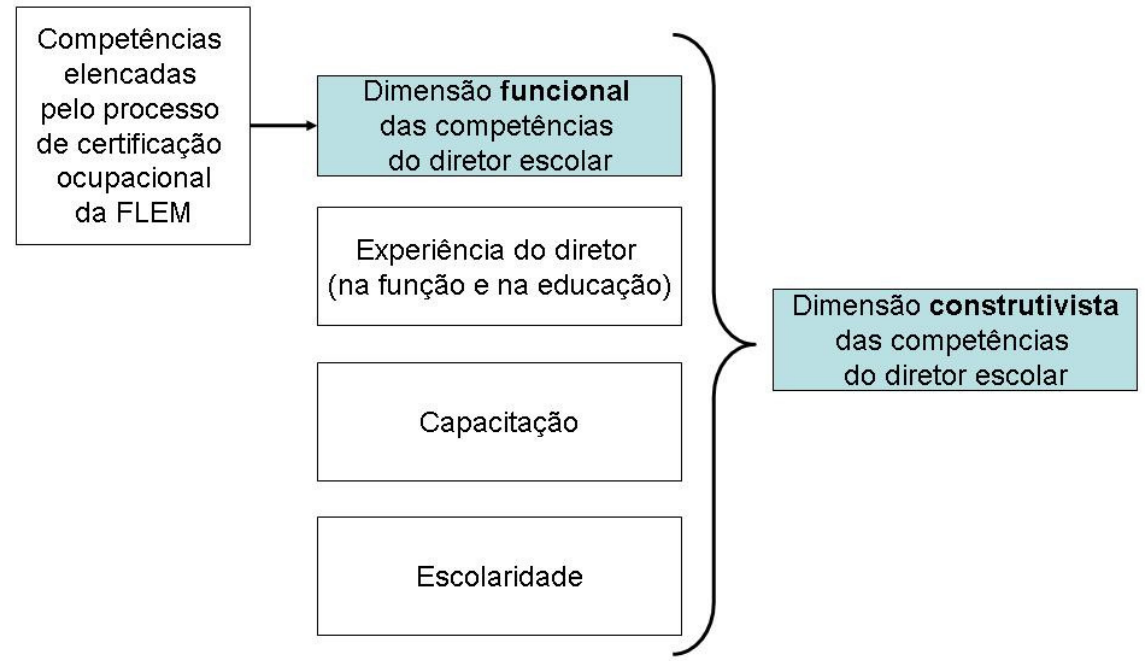

* Elaborada pelo autor.

\section{Desempenho Escolar}

O conceito de desempenho está vinculado às ideias de entrega de resultado e de qualidade que, a depender da natureza da organização, pode variar. A Lei de Diretrizes e Bases da Educação (LDB) estabelece que "[...] a educação, dever da família

112 - Est. Aval. Educ., São Paulo, v. 21, n. 45, p. 107-126, jan./abr. 2010 
e do Estado, inspirada nos princípios de liberdade e nos ideais de solidariedade humana, tem por finalidade o pleno desenvolvimento do educando, seu preparo para o exercício da cidadania e sua qualificação para o trabalho" (Brasil, 1996, Art. 2o), evidenciando a entrega, o resultado e a qualidade desejados nos serviços oferecidos pelas unidades escolares.

Para efeito deste artigo, será considerado como desempenho escolar o percentual médio de alunos proficientes em português ${ }^{1}$, da $4^{\mathrm{a}}$ e $8^{\mathrm{a}}$ séries do ensino fundamental e da $3^{a}$ série do ensino médio, nas avaliações externas do ensino realizadas em 2004. Tal percentual foi obtido a partir de dados do Projeto de Avaliaçáo Externa do Ensino, realizado pela Universidade Federal da Bahia (UFBA) e financiado pela SEC, de 1999 a 2004.

O desempenho dos alunos é medido em uma escala composta por quatro níveis, cada um deles associado a uma descrição geral que informa, por meio de "conceitos", como determinado grupo de alunos foi avaliado em relação às competências que deveriam estar dominando ao final do ano letivo. A UFBA considera proficiente o aluno que, conforme a figura 2, obtém desempenho médio ou bom nos testes do Projeto de Avaliação Externa (Universidade..., 2004).

Figura 2 - Linha de proficiência dos alunos

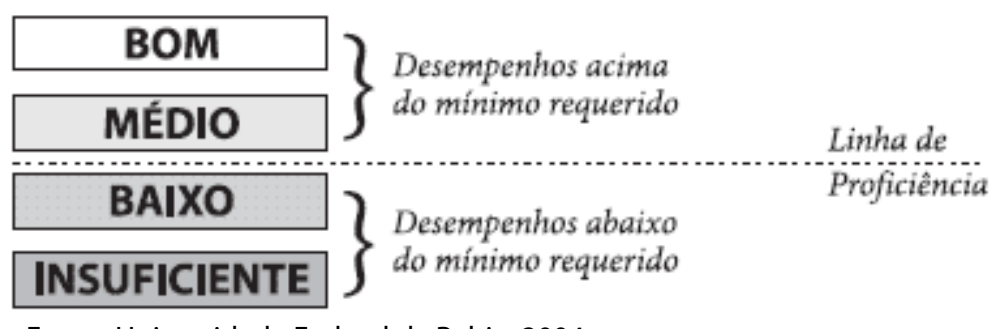

Fonte: Universidade Federal da Bahia, 2004.

\section{QUADRO OPERACIONAL}

A ideia inicial desta investigação nasceu da curiosidade em saber a influência do processo de certificação de competências ocupacionais para dirigente escolar, enquanto política pública empreendida pelo governo do Estado da Bahia, no de-

\footnotetext{
1 Apesar de o Projeto de Avaliação Externa possuir dados de matemática, optou-se por não trabalhar com eles, uma vez que, na oitava série, apenas $0,3 \%$ dos alunos foram considerados proficientes, o que prejudicaria as análises (Bahia, 2005).
} 
sempenho de suas organizaçóes escolares. Espera-se que os profissionais certificados sejam mais competentes e, portanto, produzam melhores resultados para as suas organizaçóes que os profissionais náo certificados.

Dessa maneira, a pergunta de partida foi: "Como as competências ocupacionais dos dirigentes escolares relacionaram-se com o desempenho das escolas estaduais da Bahia?" Espera-se, portanto, que as competências do diretor escolar estejam associadas aos resultados escolares, mesmo que essa associação, como sugere Soares (2005), seja indireta. Dessa forma, a primeira hipótese (H1) levantada refere-se à seguinte afirmaçáo: as competências do dirigente escolar, derivadas da análise funcional, relacionam-se positivamente com o desempenho escolar, ou seja, os diretores mais competentes, na perspectiva funcional, estão associados às escolas de mais alto desempenho.

A segunda hipótese $(\mathrm{H} 2)$ trabalha incrementando o conceito de competência ao acrescentar, aos dados funcionais, outros atributos relacionados à dimensão construtivista, como a experiência e a escolaridade. Essa hipótese prediz que as competências do dirigente escolar, ampliadas pelo modelo construtivista, relacionam-se com mais intensidade com o desempenho escolar que as competências derivadas apenas do modelo funcional.

As definiçóes dos conceitos de competência do diretor escolar e de desempenho da escola, trabalhados nesta investigação e descritos anteriormente, possibilitaram a criação do quadro operacional, apresentado na tabela 1 a seguir.

Os dados oriundos do Censo Escolar 2004, de forma geral, delimitaram o universo da pesquisa. De acordo com o Censo (Brasil, 2004), existiam na Bahia 1867 unidades escolares na rede estadual de ensino. O critério para a utilização de escolas desta base foi a gestáo do diretor no ano letivo de 2004 e sua participaçáo no processo de certificação ocupacional promovido pela FLEM, ou seja, foram consideradas apenas as escolas em que os diretores influenciaram/atuaram diretamente naquele ano letivo. Para tanto, foi necessário identificar aqueles que haviam sido designados antes do início do ano letivo e permanecido na função até o fim do mesmo ano, assim como tinham participado do processo de certificaçáo ocupacional promovido pela FLEM. Do total geral de escolas apontadas no Censo Escolar 2004, 1449 delas possuíam diretores que atendiam ao critério estabelecido. As demais 418 unidades escolares não foram consideradas no estudo.

114 - Est. Aval. Educ., São Paulo, v. 21, n. 45, p. 107-126, jan./abr. 2010 
Tabela 1 - Quadro operacional*

\begin{tabular}{|c|c|c|c|c|c|}
\hline Conceito & Dimensão & Componente & Subcomponente & Indicador & $\begin{array}{l}\text { Fonte de } \\
\text { Dados }\end{array}$ \\
\hline \multirow[t]{3}{*}{$\begin{array}{l}\text { Desempenho } \\
\text { escolar }\end{array}$} & \multirow[t]{3}{*}{ Proficiência } & \multirow[t]{3}{*}{$\begin{array}{l}\text { Desempenho } \\
\text { dos alunos no } \\
\text { teste de } \\
\text { português }\end{array}$} & $\begin{array}{l}\text { 4a série Ensino }^{\text {Fundamental }}\end{array}$ & $\begin{array}{l}\text { Percentual de } \\
\quad \text { alunos } \\
\text { proficientes em } \\
\text { português na } 4^{\mathrm{a}} \\
\text { série Ensino } \\
\text { Fundamental } \\
\text { (P4EF) }\end{array}$ & \multirow[t]{3}{*}{ SEC/UFBA } \\
\hline & & & $\begin{array}{l}8^{\text {a }} \text { série Ensino } \\
\text { Fundamental }\end{array}$ & $\begin{array}{l}\text { Percentual de } \\
\quad \text { alunos } \\
\text { proficientes em } \\
\text { português na 8a } \\
\text { série Ensino } \\
\text { Fundamental } \\
\text { (P8EF) }\end{array}$ & \\
\hline & & & $\begin{array}{l}\text { 3a série Ensino } \\
\text { Médio }\end{array}$ & $\begin{array}{l}\text { Percentual de } \\
\quad \text { alunos } \\
\text { proficientes em } \\
\text { português na 3a } \\
\text { série Ensino } \\
\text { Médio (P3EM) }\end{array}$ & \\
\hline \multirow[t]{5}{*}{$\begin{array}{l}\text { Competência } \\
\text { do diretor }\end{array}$} & Funcional & \multicolumn{2}{|c|}{$\begin{array}{l}\text { Desempenho no processo de } \\
\text { certificação }\end{array}$} & $\begin{array}{l}\text { Desempenho na } \\
\text { certificação } \\
\text { (DESEMP_CERT) }\end{array}$ & \multirow[t]{4}{*}{ SEC/FLEM } \\
\hline & \multirow[t]{4}{*}{ Construtivista } & \multirow[t]{2}{*}{ Experiência } & Na educação & $\begin{array}{c}\text { Anos de } \\
\text { experiência na } \\
\text { educação } \\
\text { (EXP_EDU) }\end{array}$ & \\
\hline & & & Na ocupação & $\begin{array}{c}\text { Anos de } \\
\text { experiência na } \\
\text { função (EXP_FUN) }\end{array}$ & \\
\hline & & \multicolumn{2}{|c|}{ Escolaridade } & $\begin{array}{l}\text { Última titulação } \\
\text { (ESCO) }\end{array}$ & \\
\hline & & \multicolumn{2}{|c|}{ Capacitação } & $\begin{array}{l}\text { Capacitação } \\
\text { recente (CAPC) }\end{array}$ & SEC/UFBA \\
\hline
\end{tabular}

Da SEC/FLEM originaram-se os dados componentes das variáveis independentes, ou seja: Desempenho na Certificação (DESEMP_CERT), Anos de experiência na educação (EXP_EDU), Anos de experiência na função (EXP_FUN) e Última Titulação (ESCO). Por fim, os dados da variável Capacitação Recente (CAPC) eram provenientes da SEC/UFBA. Os dados de proficiência dos alunos em português [(P4EF), (P8EF) e (P3EM)], oriundos do Projeto de Avaliação Externa do Ensino, foram os referentes às variáveis dependentes do desempenho escolar.

A amostra final de escolas, com dados do diretor e do percentual de proficiência dos alunos em português, considerando o critério estabelecido e a disponibilidade de dados cruzados (variáveis dependentes e independentes), foi composta por 310 
para a $4^{\mathrm{a}}$ série do ensino fundamental, 489 para a $8^{\mathrm{a}}$ série do ensino fundamental e 341 escolas para a $3^{\text {a }}$ série do ensino médio.

Utilizou-se o software SPSS como instrumento de análise estatística. Como procedimentos metodológicos de pesquisa, primeiro, foram correlacionadas as variáveis dependentes com a variável independente. Técnica denominada de Análise de Correlação Linear Simples, sendo utilizada para determinar em que medida uma variável está associada (ou dependente) a outra variável (Bussab; Morettin, 2005; Milone; Angelini, 1995). Como as variáveis possuíam distribuição normal de suas frequências, foi utilizada a correlação de Pearson, representada por (r). Em seguida, fez-se o teste do nível de significância, sendo considerados significativos os resultados em que $\alpha \leq 0,05$.

Por fim, os resultados foram confrontados com fatores de teste. A ideia trazida por Rosemberg (1968) é introduzir uma terceira variável (fator de teste), teoricamente associada às outras, e observar se a relação original se inverte, se anula ou se mantém. Para esse tipo de análise, foi utilizada a técnica de Regressão Linear Múltipla. Os fatores de testes utilizados foram: o porte da escola; a complexidade da gestão; a existência de projeto pedagógico; a disponibilidade de livros; as condiçóes de trabalho, o Índice de Desenvolvimento Humano Municipal (IDHM); e a idade do diretor, indicador apenas utilizado na segunda hipótese.

\section{RESULTADOS}

\section{Primeira Hipótese}

Para testar a Hipótese 1, como primeiro passo analítico, foram feitas correlaçóes lineares simples entre o indicador da competência dos diretores escolares na dimensão funcional (DESMP_CERT) e cada um dos indicadores do desempenho escolar (P4EF; P8EF; P3EM), das unidades escolares pertencentes à rede estadual de ensino da Bahia em 2004. Uma vez que esses dados são quantitativos, contínuos e apresentam uma distribuição normal de suas frequências, utilizou-se a correlação de Pearson. Como segundo passo, foram testados os resultados obtidos pelas correlaçóes, por meio da introduçáo de fatores de teste. Para tanto, foram realizadas regressóes lineares múltiplas.

Os resultados obtidos apontam que todas as relaçóes estabelecidas entre os indicadores de desempenho da escola e a competência do diretor escolar são positivas, ou seja, com os dados estudados de 2004, diretores com maior desempenho no processo de certificação da FLEM e, com isso, maior grau de competência funcional, estâo relacionados às escolas em que os alunos obtiveram maior desempenho em

116 • Est. Aval. Educ., São Paulo, v. 21, n. 45, p. 107-126, jan./abr. 2010 
testes padronizados, aplicados pelo Projeto de Avaliaçáo Externa da SEC/UFBA. A tabela 2 a seguir demonstra os resultados dessa análise.

Tabela 2 - Correlação entre os indicadores do desempenho da escola e o indicador da competência do diretor escolar na dimensão funcional*

\begin{tabular}{l|c|c|c|c}
\hline $\begin{array}{l}\text { Indicador da competência do diretor na } \\
\text { dimensão funcional (DESMP_CERT) }\end{array}$ & \multirow{2}{*}{$\begin{array}{c}\text { Correlação } \\
\text { Pearson }\end{array}$} & \multicolumn{3}{|c}{$\begin{array}{c}\text { Indicadores do desempenho } \\
\text { da escola }\end{array}$} \\
\cline { 3 - 5 } & & $\mathrm{P} 4 \mathrm{EF}$ & $\mathrm{P} 8 \mathrm{EF}$ & $\mathrm{P3EM}$ \\
\cline { 2 - 5 } & $\mathrm{r}$ & 0,089 & 0,133 & 0,146 \\
\cline { 2 - 5 } & $\mathrm{a}$ & 0,118 & 0,003 & 0,007 \\
\cline { 2 - 5 } & $\mathrm{n}$ & 310 & 489 & 341 \\
\hline
\end{tabular}

* Elaborada pelo autor

Entretanto, é importante citar que as relaçóes entre os indicadores, apesar de positivas, foram significativas $(\alpha \leq 0.05)$ apenas para a proficiência dos alunos em português da oitava série do ensino fundamental e da terceira série do ensino médio. A relação entre os indicadores não foi significativa para a proficiência dos alunos em português da quarta série do ensino fundamental. Outro fato que deve ser colocado em evidência é a aparente baixa correlação dessas relaçóes (máximo de $r=0,146$ em P3EM).

Diante desses resultados, utilizou-se como segundo passo analítico a introdução de fatores de teste, a fim de ampliar a compreensão das relaçóes encontradas.

Com exceção da introdução do IDHM nas relações da $8^{a}$ série do ensino fundamental e da $3^{\text {a }}$ série do ensino médio, assim como do PORTE e DISP_LIV nas relaçóes da $3^{\text {a }}$ série do ensino médio, todos os outros fatores de teste, isoladamente, confirmaram as relaçóes originais entre os indicadores do desempenho da escola e da competência do diretor escolar. Ou seja, apesar de o IDHM externamente enfraquecer a relaçáo original, a maioria dos fatores de teste internos à escola valida os dados apresentados na tabela 2.

Não obstante, em todas as análises, a competência do diretor se relacionar positivamente com o desempenho da escola, pode-se concluir que, após a introdução dos fatores de teste, a Hipótese 1 é confirmada com dados significativos $(\alpha \leq 0.05)$ em relação à maioria dos fatores internos à escola, e não é confirmada perante o fator externo à escola. Essa conclusão frustra, em parte, as expectativas iniciais de que a competência do diretor escolar, na dimensão funcional, relaciona-se positivamente com o desempenho da escola, revelando uma tendência/possibilidade de que isto seja verdadeiro. 
Compreendendo o conceito de competência da mesma forma que a FLEM o compreende, ou seja, um conjunto de conhecimentos, habilidades e atitudes indispensáveis ao exercício de uma atividade específica, é possível admitir que as competências dos diretores escolares não se relacionem com o desempenho escolar? A conclusão da Hipótese 1, quanto ao fator de teste IDHM e à luz da teoria sobre competência, apresentada na revisão da literatura, é, à primeira vista, contraditória. Caso a competência não se associe empírica e significativamente ao desempenho, o que faz sentido no movimento acerca do enfoque da competência nas organizaçóes? Qual seria a finalidade de teorias sobre as competências essenciais nas organizaçóes, gestão de competência ou formação por competência?

A bem da verdade, o resultado da Hipótese 1 náo vai de encontro às correntes teóricas sobre competência ou determinantes do desempenho escolar. Os resultados das associaçóes da competência do diretor e dos outros fatores relacionado à escola, enfraquecidos na presença do IDHM e aparentemente contraditórios à teoria, podem ser frutos de uma dessas possíveis causas:

- O IDHM, apesar de ser um índice que avalia um conjunto de indicadores associados ao nível educacional, renda e saúde de uma população, talvez não seja o melhor indicador do nível socioeconômico dos alunos, tendo em vista que o IDHM mede o desenvolvimento de um município e não o de uma comunidade escolar. Nesse sentido, em um município podem existir inúmeras escolas com perfis socioeconômicos bastante distintos.

- O recorte temporal utilizado na pesquisa pode ser insuficiente para avaliar a associação entre os indicadores dos conceitos de competência do diretor escolar, dos fatores de teste e o desempenho da escola. Nessa perspectiva, dados longitudinais ajudariam a esclarecer se essa é uma causa plausível.

- A proficiência do aluno pode estar indiretamente associada à competência do diretor escolar, como sugere o modelo conceitual de Soares (2005). De acordo com esse modelo, estariam diretamente relacionados à influência do diretor os recursos físicos, humanos e pedagógicos, a organização social e o projeto pedagógico.

- As competências funcionais dos diretores escolares, identificadas pelo processo de análise de cargos da FLEM, podem não ser as competências determinantes para o desempenho cognitivo dos alunos. Neste caso, possuir maior desempenho na certificação da FLEM se associaria a outras dimensôes do desempenho escolar. Um exemplo disso são as relaçóes significativas entre a certificação das competências dos diretores e a capacidade de

- Est. Aval. Educ., São Paulo, v. 21, n. 45, p. 107-126, jan./abr. 2010 
implementar o planejamento estratégico de forma autônoma, encontradas por Teixeira (2006).

\section{Segunda Hipótese}

Foram necessários os seguintes passos para a análise da Hipótese 2: 10) compreender como os atributos de competência (experiência na educação, experiência na função, escolaridade e capacitação) se relacionam com o indicador DESMP_CERT, que representa a dimensão funcional do conceito de competência; $2^{\circ}$ ) a partir dos atributos de competência, formar um índice que represente a competência na dimensão construtivista; $3^{\circ}$ ) correlacionar o índice de competência na dimensão construtivista a cada um dos indicadores do desempenho escolar de 2004; $4^{\circ}$ ) comparar os resultados obtidos com o índice de competência na dimensão construtivista com aqueles obtidos com o indicador de competência na dimensão funcional, já analisados na primeira hipótese; 50) testar os resultados obtidos por meio da introdução de fatores de teste.

Para a compreensão do índice responsável por representar a dimensão construtivista do conceito de competência do diretor escolar, foi necessário correlacionar os atributos de competência utilizados na pesquisa (experiência na educação, experiência na função, escolaridade e capacitação) com o indicador de competência na dimensão funcional (DESMP_CERT).

As relaçôes originais foram testadas, por meio da análise de regressão linear múltipla, com a introdução do fator de teste "idade" do diretor. Por meio dessa análise, ficou identificado que o atributo de competência "experiência na educação", representada pelo indicador EXP_EDU, não se correlaciona com o desempenho na certificaçáo. A relação original entre os dois indicadores é espúria, ou seja, anulou-se ao introduzir o fator de teste "idade".

As outras relaçóes foram originalmente significativas e permaneceram assim após a introdução do fator de teste "idade". Entretanto, os atributos de competência "escolaridade" e "capacitação" se relacionam positivamente com o desempenho na certificação, ao passo que a "experiência na funçáo" se relaciona negativamente.

Compreendidas as relaçóes internas entre os atributos de competência com DESMP_CERT, iniciou-se o segundo passo, objetivando estabelecer, propriamente, o índice que representasse a dimensão construtivista do conceito de competência. Para tanto, inicialmente, foram correlacionados os atributos de competência a cada um dos indicadores do desempenho escolar, no intuito de identificar futuras influências de cada componente do índice. 
Concernente ao sentido dessas correlações, conforme pode ser observado na tabela 3, os atributos de competência se correlacionam homogeneamente com os indicadores do desempenho escolar, ou seja, a predominância é de correlaçóes positivas. Entretanto, essa homogeneidade não é obtida quanto à significância das relações. Isso implica imaginar que os atributos de competência, agindo em conjunto, podem influenciar positivamente as relaçóes com os indicadores do desempenho escolar, apesar de alguns possuírem dados pouco significativos. Ademais, como alguns atributos de competência não se correlacionam ou se correlacionam negativamente entre si - é o caso da experiência na função e na educação em relação ao desempenho na certificação -, pode haver um efeito compensador em função do desempenho escolar.

Tabela 3 - Correlação entre atributos de competência e desempenho escolar*

\begin{tabular}{l|c|c|c|c}
\hline \multirow{2}{*}{ Atributos de competência } & \multirow{2}{*}{ Correlação Pearson } & \multicolumn{3}{|c}{ Indicadores do desempenho escolar } \\
\cline { 2 - 4 } & & P4EF & P8EF & P3EM \\
\hline Desempenho na certificação & $\mathrm{r}$ & 0,089 & 0,133 & 0,146 \\
\cline { 2 - 5 } & $\mathrm{a}$ & 0,118 & 0,003 & 0,007 \\
\cline { 2 - 5 } & $\mathrm{n}$ & 310 & 489 & 341 \\
\hline \multirow{2}{*}{ Escolaridade } & $\mathrm{r}$ & 0,106 & 0,137 & 0,162 \\
\cline { 2 - 5 } & $\mathrm{a}$ & 0,064 & 0,003 & 0,003 \\
\hline \multirow{2}{*}{ Experiência na Função } & $\mathrm{n}$ & 304 & 485 & 338 \\
\cline { 2 - 5 } & $\mathrm{r}$ & 0,200 & 0,040 & $-0,015$ \\
\cline { 2 - 5 } & $\mathrm{a}$ & 0,001 & 0,394 & 0,799 \\
\hline \multirow{2}{*}{ Experiência na Educação } & $\mathrm{n}$ & 290 & 453 & 297 \\
\cline { 2 - 5 } & $\mathrm{r}$ & 0,139 & 0,038 & 0,027 \\
\cline { 2 - 5 } & $\mathrm{a}$ & 0,020 & 0,435 & 0,645 \\
\hline Capacitação & $\mathrm{n}$ & 279 & 431 & 300 \\
\cline { 2 - 5 } & $\mathrm{r}$ & 0,078 & 0,110 & 0,196 \\
\cline { 2 - 5 } & $\mathrm{a}$ & 0,108 & 0,056 & 0,011 \\
\hline
\end{tabular}

* Elaborada pelo autor.

Considerando esse comportamento, foi realizado um modelo de índice composto por indicadores quantitativos discretos dos atributos de competência (DESMP CERT, ESCOLARIDADE, EXP_FUN, EXP_EDU e CAPC), ou seja, os dados dos atributos de competência foram transformados em valores 0 ou 1 para a composição do índice. $\mathrm{O}$ valor 0 (zero) foi atribuído aos valores inferiores ao percentil 50 de cada indicador/atributo. $\mathrm{O}$ valor 1 (um) foi atribuído aos valores superiores ao percentil 50 de cada indicador/atributo, conforme a tabela 4 . 
Tabela 4 - Composição do índice de competência na dimensão construtivista*

\begin{tabular}{l|c|c|c|c}
\hline Indicador/atributo & $\begin{array}{c}\text { Menores e } \\
\text { maiores } \\
\text { valores }\end{array}$ & $\begin{array}{c}\text { Percentil } \\
\mathbf{5 0}\end{array}$ & $\begin{array}{c}\text { Frequência de dados } \\
\text { com valores inferiores } \\
\text { ao percentil 50 (valor 0) }\end{array}$ & $\begin{array}{c}\text { Frequência de dados } \\
\text { com valores superiores } \\
\text { ao percentil 50 (valor 0) }\end{array}$ \\
\hline DESMP_CERT & $0 ; 3,68$ & 2,21 & $603(50,5 \%)$ & $590(49,5 \%)$ \\
\hline ESCOLARIDADE & $1 ; 6$ & 3 & $534(45,4 \%)$ & $643(54,6 \%)$ \\
\hline EXP_FUN & 1,$0 ; 34,0$ & 5,63 & $461(48,6 \%)$ & $488(51,4 \%)$ \\
\hline EXP_EDU & 0,$1 ; 97,3$ & 7,83 & $531(50,1 \%)$ & $528(49,9 \%)$ \\
\hline CAPC & $0 ; 1$ & - & $148(26,7 \%)$ & $406(73,3 \%)$ \\
\hline * Elaborada pelo autor. & \multicolumn{4}{l}{}
\end{tabular}

O índice de competência do diretor escolar na dimensão construtivista, codificado como ICC, foi calculado pela soma dos valores de cada indicador/atributo de competência da tabela 4 , podendo variar de 0 a 5 .

Depois de calculado o ICC, iniciou-se o terceiro passo analítico dessa hipótese, em que este índice foi relacionado com os indicadores do desempenho escolar por meio da correlação linear simples. Os resultados dessas correlaçóes estão na tabela 5.

Tabela 5 - Relações entre o índice de competência do diretor escolar na dimensão construtivista e os indicadores de desempenho*

\begin{tabular}{l|c|c|c|c}
\hline $\begin{array}{l}\text { Índice de competência do diretor na } \\
\text { dimensão construtivista (ICC) }\end{array}$ & \multirow{2}{*}{$\begin{array}{c}\text { Correlação } \\
\text { Pearson }\end{array}$} & \multicolumn{3}{|c}{$\begin{array}{c}\text { Indicadores do desempenho } \\
\text { da escola }\end{array}$} \\
\cline { 3 - 5 } & & $\mathrm{P} 4 \mathrm{EF}$ & $\mathrm{P} 8 \mathrm{EF}$ & $\mathrm{P} 3 \mathrm{EM}$ \\
\cline { 2 - 5 } & $\mathrm{r}$ & 0,151 & 0,203 & 0,234 \\
\cline { 2 - 5 } & $\mathrm{a}$ & 0,008 & 0,000 & 0,000 \\
\cline { 2 - 5 } & $\mathrm{n}$ & 310 & 489 & 341 \\
\hline * Elaborada pelo autor. & \multicolumn{3}{l}{}
\end{tabular}

* Elaborada pelo autor.

Constatando que todas as relações da tabela 5 foram positivas e significativas, seguiu-se para o próximo passo metodológico: comparar os resultados obtidos das relações entre as dimensóes funcional e construtivista do conceito de competência do diretor escolar, estabelecidas com os indicadores do desempenho da escola. Para facilitar essa comparação, foi elaborado o gráfico a seguir. 
Figura 3 - Dimensão funcional x dimensão construtivista*

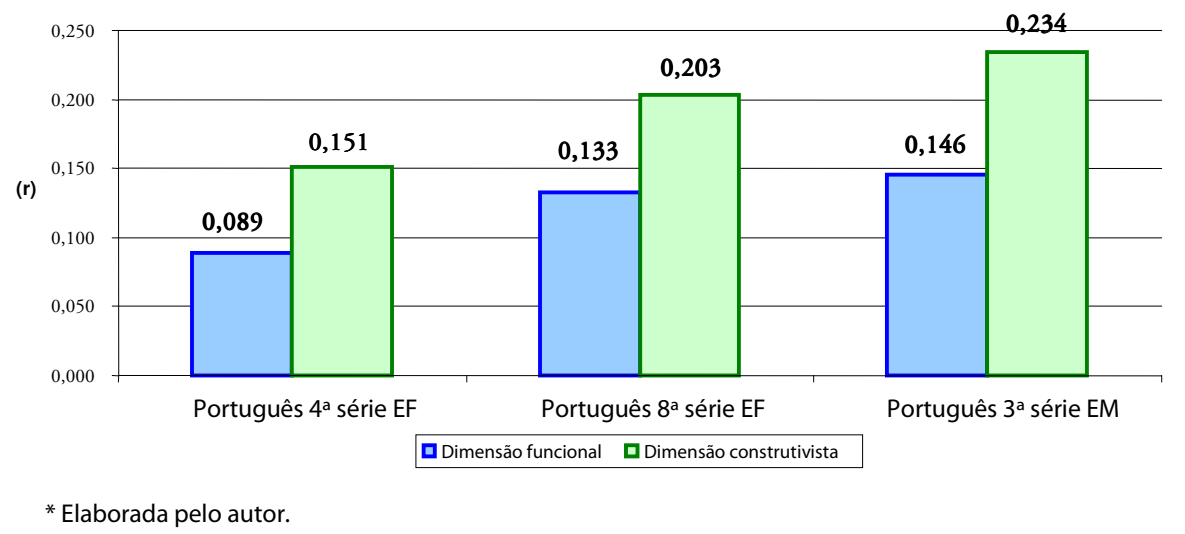

Como demonstra a figura 3, para todos os indicadores do conceito de desempenho escolar, as relaçóes estabelecidas com a dimensáo construtivista do conceito de competência do diretor escolar são mais intensas e mais significativas que as relaçóes estabelecidas com a dimensáo funcional. Confirma-se, assim, a Hipótese 2 de que a competência construtivista do dirigente escolar se relaciona com mais intensidade com o desempenho escolar que a competência funcional.

Para finalizar os passos analíticos da Hipótese 2 e aumentar a compreensão sobre as relaçóes estabelecidas entre o ICC e os indicadores de desempenho escolar, resta submeter as relações à presença de fatores de teste. Uma vez que o IDHM foi o fator de maior relevância na análise da Hipótese 1, submeteremos as relaçóes originais de $\mathrm{H} 2$ apenas ao IDHM.

Como resultado, a presença do fator de teste IDHM retirou a significância da relação original entre ICC e P4EF, seguindo a tendência do que ocorreu na Hipótese 1. Entretanto, nas relações entre ICC e P8EF e P3EM, o IDHM não retirou a significância do modelo. Isto implica concluir que, além de mais significativa e mais intensa que as relaçôes estabelecidas com a competência na dimensão funcional, duas, de três relaçóes entre os indicadores de desempenho e o ICC, são confirmadas, mesmo após a introdução do fator de teste IDHM.

Confirmada a Hipótese 2, a seguir são destacados conhecimentos revelados durante os procedimentos metodológicos que merecem comentários:

- A não esperada correlação negativa entre os atributos de competência "desempenho na certificação" e "experiência na educação". Considerando que o processo de certificação da SEC/FLEM está relacionado às competências 
efetivas dos profissionais no trabalho (Fundação..., 2000c, apud D’Almeida, 2003), esperava-se que a experiência estivesse altamente relacionada com o desempenho dos diretores na referida certificação. Corroborando essa expectativa, o conceito empregado pela OIT (2002) para certificação ocupacional $^{2}$ revela a importância do reconhecimento da experiência do profissional em um processo de certificação. Entretanto, as correlaçóes estabelecidas entre o desempenho na certificaçáo e os outros atributos de competência indicam a aproximação do processo de certificação da SEC/FLEM apenas com a escolaridade e a capacitação.

- A tabela 3 revelou que os atributos de competência, utilizados para compor o ICC, relacionam-se com diferentes intensidades com os indicadores do desempenho escolar. $\mathrm{O}$ desempenho do diretor no processo de certificação, assim como a escolaridade e a capacitação, estão mais associados aos indicadores da $8^{a}$ série do ensino fundamental e da $3^{a}$ série do ensino médio. As experiências dos diretores (na educação e na função) estão mais relacionadas ao indicador da $4^{\mathrm{a}}$ série do ensino fundamental.

- Essa diferenciaçáo nas associaçóes, apresentada no item anterior, revela uma possível limitação no cálculo do ICC. Nesta investigação todos os indicadores/atributos de competência tiveram o mesmo peso na composição do ICC, ou seja, cada indicador/atributo contribuiu com 1/5 do total. Algumas questões surgem a partir dessa constatação: seria essa uma distribuição de pesos correta? Atribuindo pesos diferentes aos indicadores/atributos de competência na formulação do ICC obteríamos melhores resultados? Os pesos seriam os mesmos, independentemente do indicador de desempenho escolar? Qual seria o melhor método para definição dos pesos dos indicadores/atributos de competência na composição do ICC?

Embora uma das três regressóes tenha perdido significância após a introdução do fator de teste IDHM, o ganho de intensidade nas relações estabelecidas entre

\footnotetext{
${ }^{2}$ Conceito de certificação ocupacional: "Procedimento pelo qual se atesta a conformidade de uma pessoa a normas correspondentes a uma ocupação. É o reconhecimento ou o atestado expedido por órgão reconhecido e credenciado, da aptidáo plena no exercício das tarefas e operaçôes de uma ocupação para o trabalhador experiente, mesmo que não tenha cursado um sistema regular de formação (Organização..., 2002, p. 20).
} 
o ICC e os indicadores do desempenho escolar, diante dos valores encontrados na Hipótese 1, revelam empiricamente a importância da experiência da capacitação e da escolaridade para os resultados de uma organizaçáo.

\section{CONSIDERAÇÕES FINAIS}

No contexto de mudanças tecnológicas, globalização e acirramento da competitividade internacional, em que o conceito de competência surge e ganha espaço nas políticas governamentais, os resultados encontrados nesta investigação revelam empiricamente uma correlação positiva entre a competência ocupacional do diretor escolar, nas dimensóes funcional e construtivista, e o desempenho das escolas da rede estadual de ensino da Bahia.

Às políticas públicas, os resultados dessa pesquisa contribuem para a confirmação da importância da competência ocupacional para o alcance de resultados organizacionais, mesmo que o efeito dessa competência seja indireto. Dessa maneira, políticas que valorizem o mérito profissional e a profissionalização da escolha do quadro de funcionários, principalmente para a liderança de escolas públicas, são de extrema importância no cenário atual.

A tendência positiva encontrada no desempenho acadêmico dos alunos - em português -, confirmada pelos fatores de teste, validou a hipótese final de que as competências ocupacionais do dirigente escolar, no modelo construtivista, relacionam-se de maneira mais intensa e significativa com o desempenho escolar que as competências analisadas no modelo funcional. Essa descoberta influencia diretamente no método utilizado para a realização de processos de certificação ocupacional no Brasil.

Os achados desta investigação lançam questóes a serem tratadas por governos e organizaçóes que promovem certificaçáo de pessoas. A ampliaçáo do conceito de competência, do modelo funcional para o construtivista, sugere novas formas de avaliação e capacitação profissional, que valorizem trajetórias e competências muitas vezes despercebidas aos métodos tradicionais de certificação e avaliação de desempenho. Entretanto, algumas consideraçóes merecem ser feitas:

1. A correlação entre duas variáveis não implica que essa associação seja de causa e efeito. Apesar de os resultados serem todos positivos, não quer dizer que a maior competência do diretor escolar seja a causa de um maior desempenho acadêmico de seus alunos. Para se chegar a essa conclusão, uma pesquisa mais aprofundada deveria ser feita, inclusive utilizando análise longitudinal de dados. Além disso, os danos atuais, por não serem hierárquicos, não permitem analisar possíveis variaçóes dentro da própria escola, entre os alunos. 
2. A aparente baixa correlação encontrada nas hipóteses náo significa que os achados desta investigação não sejam importantes. Na literatura, é possível encontrar muitos outros fatores que, como a competência do diretor, influenciam o desempenho escolar. Soares (2005), por exemplo, analisando diversos fatores que determinam o desempenho escolar, compreende que a contribuição de um fator escolar isolado é normalmente pequena. Dessa maneira, as relações encontradas são contribuições que se somam aos outros determinantes, como: escolaridade dos pais, condições adequadas de ensino, disponibilidade de biblioteca, etc.

3. Pode haver um distanciamento entre a competência do diretor escolar e a proficiência do aluno que enfraqueça a correlação, ou seja, talvez a competência do diretor escolar influencie a proficiência do aluno de maneira indireta e mais vagarosamente. Dessa maneira, provavelmente um estudo longitudinal pudesse investigar essa questão.

4. Por fim, a competência do diretor escolar revelou ser mais importante em situaçóes mais complexas de ensino, como: séries mais avançadas, escolas de maior porte e perfil mais complexo de gestáo. Provavelmente, a maneira como a educaçáo se estrutura nas séries iniciais, com maior influência dos pais e do professor na educação dos filhos, neutralize os efeitos da eventual incompetência dos diretores escolares. Essa também é uma questấo que deve ser melhor aprofundada por futuras pesquisas.

\section{REFERÊNCIAS BIBLIOGRÁFICAS}

BAHIA. Lei no 8.261. Dispõe sobre o estatuto do magistério público do ensino fundamental e médio do Estado da Bahia e dá outras providências. DOU, 30 maio 2002. Disponível em: <http://www2.bahia.ba.gov. br/CGI-BIN/om_isapi.dll?clientID=703385 5 \&headingswith hits=on\&infobase $=$ lo\&ju $\mathrm{mp}=\mathrm{LO} \% 208.261 \&$ softpage $=$ Doc_Frame_ Pg42\#JUMPDEST_LO\%208.261>. Acesso em: 24 fev. 2007.

. Secretaria da Educação. Avaliação de desempenho 2004: resultados gerais e análises pedagógicas. Salvador, 2005.

Diretrizes e Bases da Educação Nacional. DOU, 20 dez. 1996. Disponível em: <http://www. planalto.gov.br/ccivil/LEIS/L9394.htm>. Acesso em: 24 fev. 2007.

BRASIL. Ministério da Educação. Dados_ do_Censo_Escolar_2004.xls. Salvador: MEC/ Inep/SEC, 2004.

BRASIL. Ministério do Trabalho. Sistema Nacional de Certificação Profissional: proposta governamental. Brasília: Comissão Interministerial de Certificação Profissional, 2005.

BRASIL. Leis e decretos. Lei n 9.394. Lei de BUSSAB, Wilton de O.; MORETTIN, Pedro A. 
Estatística básica. 5. ed. São Paulo: Saraiva, 2005.

D'ALMEIDA, Milena Costa. Certificação ocupacional de profissionais da educação na Bahia: análise do alinhamento entre os resultados do teste de conhecimentos específicos e da autoavaliação. 2003. Dissertação (Mestrado em Administração) - Universidade Federal da Bahia, Escola de Administração, Salvador.

FUNDAÇÃO LUÍS EDUARDO MAGALHÃES. Agência de Certificação Ocupacional. Padrão de competências do cargo de dirigente escolar. Salvador, 2001. Disponível em: <www.certifica.org.br>.

- Relatório: caso certificação ocupacional de dirigentes escolares. Salvador, 2005.

LAVILLE, Christian; DIONNE, Jean. A Construção do saber: manual de metodologia da pesquisa em ciências humanas. Porto Alegre: Artes Médicas Sul; Belo Horizontes: Editora UFMG, 1999.

MEHEDFF, Nassim Gabriel. A Avaliação da educação e a inserção dos egressos do ensino médio no mercado de trabalho. Brasília: Inep, 1999.

MERTENS, Leonard. Competencia laboral: sistemas, surgimiento y modelos. Montevideo: Cinterfor, 1996. Disponível em: <http:// www.ilo.org/public/spanish/region/ampro/ cinterfor/publ/mertens/pdf/mertens.pdf $>$. Acesso em: 24 fev. 2007.

MILONE, Giuseppe; ANGELINI, Flávio. Estatística aplicada. São Paulo: Atlas, 1995.

ORGANIZAÇÃO INTERNACIONAL DO TRABALHO. Certificação de competências profissionais: discussões. Brasília: OIT, MTE/ FAT, 1999.

Certificação de competências profissionais: glossário de termos técnicos. 1. ed. Brasília: OIT, 2002.

ROSEMBERG, Morris. A Lógica da análise do levantamento de dados. São Paulo: Cultrix, 1968.

SOARES, Francisco José. O Efeito da escola no desempenho cognitivo de seus alunos. In: SOUZA, Alberto de Mello e (Org.). Dimensões da avaliação educacional. Petrópolis: Vozes, 2005. p. 174-204.

TEIXEIRA, Janssen Edelweiss Nunes Fernandes. Análise da relação entre a certificação de dirigentes escolares e a implementação do planejamento estratégico nas escolas da rede pública estadual baiana. 2006. Dissertação (Mestrado Profissional) - Universidade Federal da Bahia, Escola de Administração, Salvador.

UNIVERSIDADE FEDERAL DA BAHIA. Projeto de avaliação externa. Salvador, 2004. Disponível em: <http://www.aval.ufba.br>. Acesso em: 21 jan. 2007.

Recebido em: setembro 2009

Aprovado para publicação em: fevereiro 2010

126 - Est. Aval. Educ., São Paulo, v. 21, n. 45, p. 107-126, jan./abr. 2010 